\title{
Correction to: Six new species of Barleria L. (Acanthaceae) from Northeast Tropical Africa
}

Ensermu Kelbessa ${ }^{1}$ \& lain Darbyshire ${ }^{2}$

\section{Correction to: KEW BULLETIN (2018) 73: 1 https://doi.org/10.1007/S12225-017-9725-2}

The original version of this article unfortunately contains an error in the title, whereby the first author's names have been inadvertently transposed. We apologise unreservedly for this error. The correct citation of the authors' names is as follows:

Ensermu Kelbessa $^{1} \&$ Iain Darbyshire ${ }^{2}$

The original article has been corrected.

1 The National Herbarium, Department of Plant Biology \& Biodiversity Management, Faculty of Science, Addis Ababa University, P.O. Box 3434, Addis Ababa, Ethiopia.

2 Herbarium, Royal Botanic Gardens, Kew, Richmond, Surrey, TW9 3AB, UK. e-mail: i.darbyshire@kew.org 